\title{
Antitumor effects of traditional Chinese medicine targeting the cellular apoptotic pathway
}

Huanli Xu'

Xin Zhao ${ }^{2}$

Xiaohui Liu'

Pingxiang $X u^{\prime}$

Keming Zhang ${ }^{2}$

Xiukun Lin'

'Department of Pharmacology, School of Basic Medical Sciences, Capital Medical University, ${ }^{2}$ Department of Hepatobiliary Surgery, 302 Hospital of Chinese People's Liberation Army, Beijing, People's Republic of China
Correspondence: Xiukun Lin Department of Pharmacology, School of Basic Medical Sciences, Capital Medical University, 10 Xitoutiao, You An Men, Beijing 100069, People's Republic of China

Tel +861083911835

Email linxiukun@yahoo.com

\begin{abstract}
Defects in apoptosis are common phenomena in many types of cancer and are also a critical step in tumorigenesis. Targeting the apoptotic pathway has been considered an intriguing strategy for cancer therapy. Traditional Chinese medicine (TCM) has been used in the People's Republic of China for thousands of years, and many of the medicines have been confirmed to be effective in the treatment of a number of tumors. With increasing cancer rates worldwide, the antitumor effects of TCMs have attracted more and more attention globally. Many of the TCMs have been shown to have antitumor activity through multiple targets, and apoptosis pathway-related targets have been extensively studied and defined to be promising. This review focuses on several antitumor TCMs, especially those with clinical efficacy, based on their effects on the apoptotic signaling pathway. The problems with and prospects of development of TCMs as anticancer agents are also presented.
\end{abstract}

Keywords: traditional Chinese medicine, antitumor effects, apoptotic pathway

\section{Introduction}

Apoptosis is a normal physiological process that plays an important role in various phases of life, for example, in embryonic development. ${ }^{1}$ Defects in apoptosis are common phenomena in many types of cancer. Modulation of apoptotic pathways and selective induction of apoptosis by chemical agents have been shown to be a promising approach in the treatment of cancer. ${ }^{2}$ It is well documented that apoptosis is a very complicated process and involves a great number of signaling molecules, and failure of induction of apoptosis is one of the major impediments to treatment of cancer. ${ }^{3,4}$ There are two signaling pathways resulting in apoptosis in mammals, ie, the extrinsic death receptor pathway and the intrinsic mitochondrial pathway. Traditional Chinese medicines (TCMs) can induce cell death via multiple targets in both the caspase-dependent and caspase-independent apoptosis pathways (Figure 1).5,6 In the past few years, various studies have suggested the existence of pathways of caspase-independent apoptosis. Many proteins, such as the proapoptotic Bax and Bid proteins, apoptosis-inducing factor, and the cathepsins, calpains, and serine proteases, are involved in caspase-independent apoptosis. ${ }^{7}$ These apoptosis pathways are regulated by a number of proapoptotic or antiapoptotic molecules. Therefore, developing anticancer agents that target these molecules has become an important strategy for cancer chemotherapy.

TCM has been used for thousands of years in the People's Republic of China, and it is recognized that cancer is caused by the invasion of external evil (exogenous pathogenic factors), heat enhancement, and frailty. Herbs with "heat and toxin-clearing" activity as well as "supplementing the center and boost the energy", can be used for cancer treatment. In recent years, TCM has gradually come to be accepted by Western countries. 


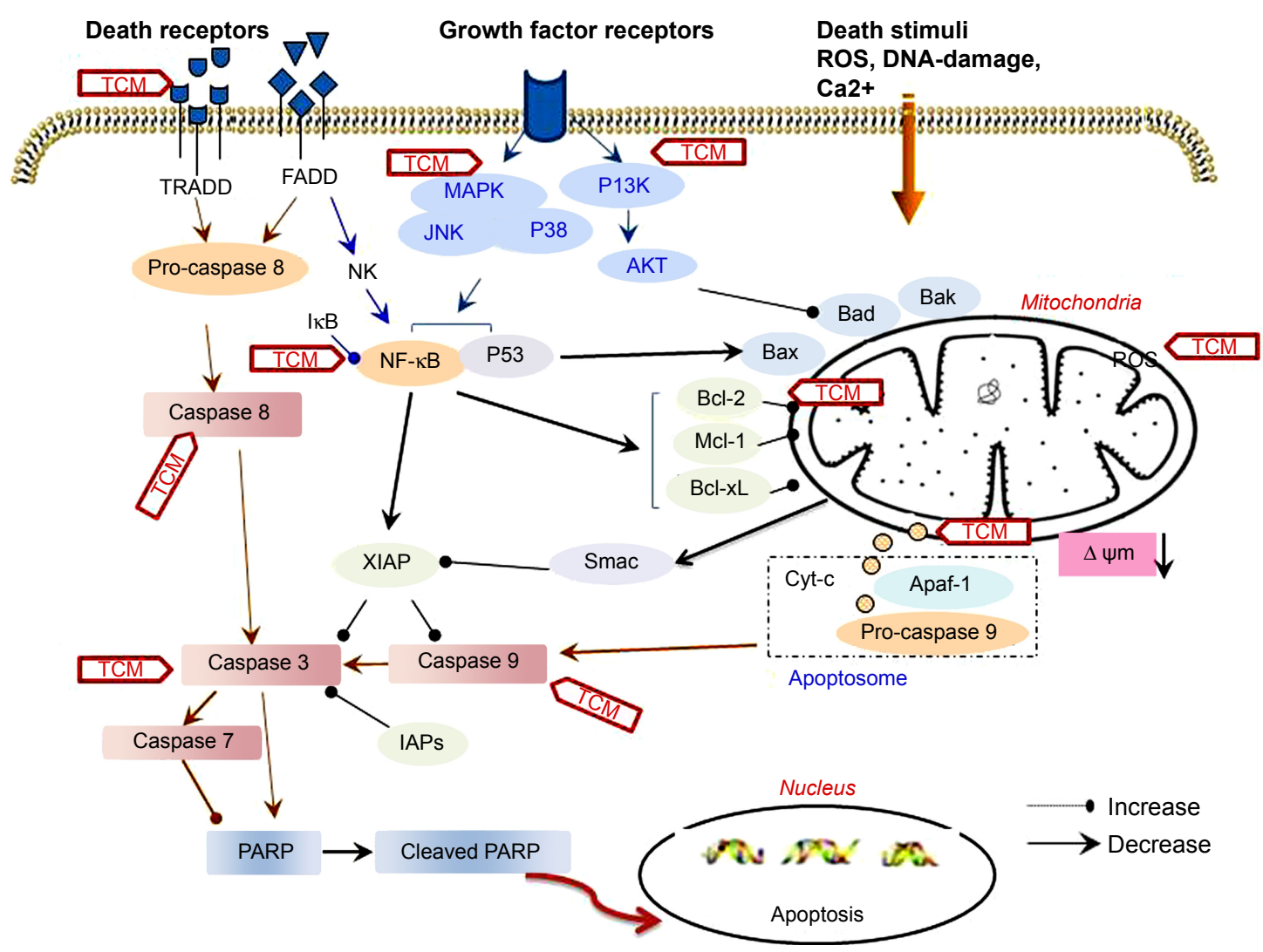

Figure I Schematic description of the mechanisms of apoptosis for TCM. Apoptosis occurs via different pathways in cells. Some TCMs can alter the ratio of Bcl-2/Bax, while others can activate caspases. ROS, MAPK, PI3K/Akt/STAT, and the NF-kappa B pathway are also involved in TCM-induced apoptosis.

Abbreviations: MAPK, mitogen-activated protein kinase; ROS, reactive oxygen species; PI3K, phosphatidylinositol-3 kinase; TCM, traditional Chinese medicine; NF- $\mathrm{KB}$, nuclear factor kappa B; TRADD, TNF receptor associated death domain; FADD, Fas associated death domain; NK natural killer; XIAP, X-linked inhibitor of apoptosis protein; IAPs, inhibitor of apoptosis proteins; PARP, poly ADP-ribose polymerase.

With increasing cancer rates worldwide, the antitumor effects of some TCMs have been attracting increasing attention. ${ }^{8}$ Some of them have been shown to have unique advantages in the treatment of certain tumors. It is becoming important to exploit the antitumor mechanisms of TCMs. ${ }^{9-11}$ This review focuses mainly on recent progress made with some anticancer TCMs that can induce apoptosis of cancer cells.

\section{TCMs that alter the $\mathrm{BCl}-2 / \mathrm{Bax}$ ratio}

The Bcl-2 family, which contains both proapoptotic and prosurvival members, plays an important role in regulating cell apoptosis. ${ }^{12}$ Bax, a proapoptotic member of Bcl-2 family, translocates to the mitochondria and inserts into the outer mitochondrial membrane, promoting mitochondria-mediated apoptosis. Bcl-2, in contrast, preserves mitochondrial integrity by preventing this process. Thus, the ratio of Bax to Bcl-2 is crucial in the mitochondria-mediated apoptosis pathway. ${ }^{13}$ Many TCMs have been found to induce cell death by regulating the balance of Bcl-2 family members.

Tumors are recognized to be the result of "Qi stagnation and blood stasis" in "Danxi's Experiential Therapy", a famous document from the ancient literature on TCM written in 1483 , and herbs able to "clear away heat and toxic material" are generally selected for treatment of cancer, including Hedyotis diffusa Willd (Rubiaceae), Solanum lyratum Thunb (Solanaceae), Garcinia hanburyi Hook. f. (Clusiaceae), and Carpesium divaricatum Sieb. and Zucc. (Compositae). ${ }^{14}$ H. diffusa Willd has been used as a major component in several Chinese medicine formulations for the treatment of various cancers. Studies have shown that $H$. diffusa injection combined with chemotherapy can significantly prolong survival and decrease the side effects of chemotherapy in patients with advanced liver cancer or esophageal cancer. ${ }^{15}$ Recent studies have shown that an ethanol extract of $H$. diffusa Willd can induce apoptotic cell death in the concentration range of $0.5-5 \mathrm{mg} / \mathrm{mL}$; treatment of HT-29 human colon carcinoma cells with an ethanol extract of $H$. diffusa Willd could induce an increase in the $\mathrm{Bax} / \mathrm{Bcl}-2$ ratio, resulting in mitochondria-mediated apoptosis. ${ }^{16}$ Injection of $H$. diffusa Willd can significantly upregulate mRNA levels of Bcl-2, interleukin-6, and vascular endothelial factor, but not Bax and caspase-3 mRNA levels. ${ }^{17}$

S. lyratum Thunb, a major herb in several Chinese medicine formulations, has immune and antitumor activity. ${ }^{18}$ 
An ethanol extract of $S$. lyratum Thunb could decrease Bcl-2 levels and increase Bax levels (ie, increase the Bax/ $\mathrm{Bcl}-2$ ratio), leading to release of cytochrome $\mathrm{c}$ from the mitochondria into the cytosol and activation of caspase- 9 and caspase-3 in U-2 OS (human osteosarcoma) cells. ${ }^{19}$ Recent studies indicate that total saponins isolated from $S$. lyratum Thunb have antitumor activity (with an $\mathrm{IC}_{50}$ of $6 \mu \mathrm{g} / \mathrm{mL}$ ) via induction of apoptosis. Induction of apoptosis by $S$. lyratum Thunb involves downregulation of Bcl-2, upregulation of Bax, and release of cytochrome c. Total alkaloids of Rubus aleaefolius Poir, used in some TCM formulations for the treatment of cancer, could increase the proapoptotic $\mathrm{Bax} / \mathrm{Bcl}-2$ ratio in mouse hepatocellular tumors at both the transcriptional and translational levels. ${ }^{20}$

Some active components of TCMs altering the Bcl-2/Bax ratio have also been identified. Gambogic acid (Figure 2),

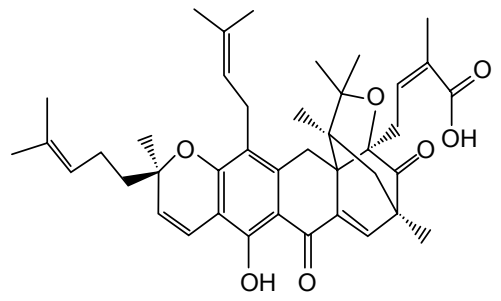

Gambogic acid<smiles></smiles>

Berberine<smiles>CC(C)=CC[C@H](O)C1=CC(=O)c2c(O)ccc(O)c2C1=O</smiles>

Shikonin

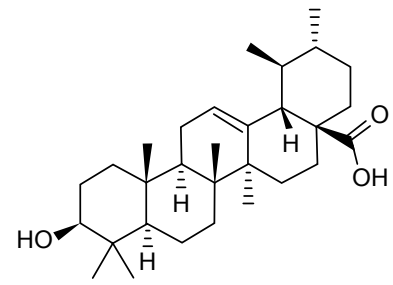

Ursolic acid

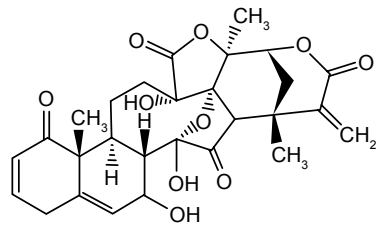

Physalin A

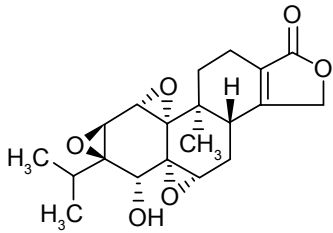

Triptolide

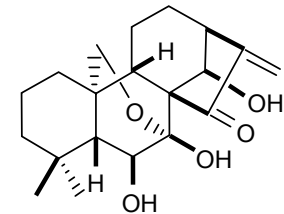

Longikaurin A

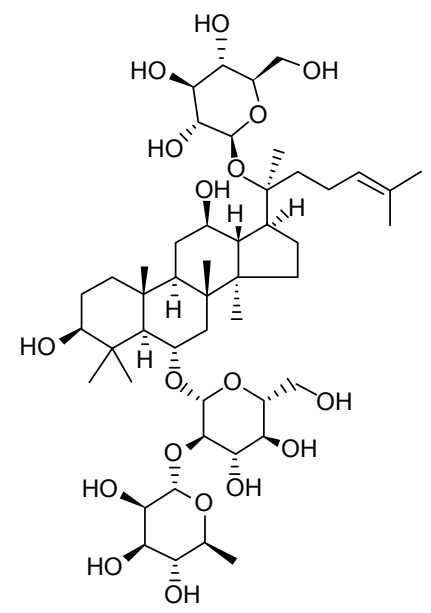

Ginsenosides<smiles>COc1cc(/C=C/C(=O)CC(=O)/C=C/c2ccc(O)c(OC)c2)ccc1O</smiles>

Curcumin<smiles>O=C(/C=C/c1ccc(O)c(O)c1)NCCc1ccc(O)cc1</smiles>

Trans-N-caffeoyltyramine<smiles>O=c1cc(-c2ccccc2)oc2ccccc12</smiles>

Common structure of flavonoids<smiles>CC1O[C@H]2OC(O)[C@@H](O)[C@]2(COC(=O)c2ccccc2)C1OC1O[C@H](CO)[C@@H](O)[C@H](O)[C@H]1O</smiles>

Paeoniflorin<smiles>O=c1c(O)c(-c2ccc(O)cc2)oc2c(O)c(O)cc(O)c12</smiles>

Bufalin

Figure 2 Some chemical structures of the active components in TCM.

Abbreviation: TCM, traditional Chinese medicine. 
a component extracted from G. hanburyi Hook. f., has antitumor effects in several types of human cancer cells, including prostate cancer, breast cancer, gastric carcinoma, hepatocellular carcinoma, and lung cancer in vitro and in vivo. ${ }^{21}$ Gambogic acid has now entered Phase II clinical trials as a treatment for various cancers. One trial showed that the clinical remission and benefit rates of gambogic acid were $14.29 \%$ and $76.19 \%$, respectively. ${ }^{22} \mathrm{~A}$ recent study showed that treatment with gambogic acid $0.5-2 \mu \mathrm{g} / \mathrm{mL}$ could induce mitochondria-dependent apoptosis by modulation of Bcl-2 and Bax in JeKo mantle cell lymphoma-1 cells. ${ }^{23}$ Additionally, telekin, isolated from C. divaricatum Sieb. and Zucc., has been reported to strongly inhibit proliferation of cancer cells. It was demonstrated that treatment with telekin $2.5-10 \mu \mathrm{mol} / \mathrm{L}$ could decrease the expression of Apaf-1 and Bcl-2, increase Bax expression, and increase the release of cytochrome $\mathrm{c}$, resulting in activation of caspase- 9 and caspase- 3 in HepG 2 cells. ${ }^{24}$

\section{TCMs that activate caspases}

Caspases are a family of cysteinyl aspartate-specific proteases involved in apoptosis and are dichotomized into groups of initiators (caspase-8, caspase-9, and caspase-10) and executioners (caspase-3, caspase-6, and caspase-7). Modulation of caspase activation is a critical molecular approach for the development of anticancer agents. ${ }^{25,26}$ Many TCMs have been found to affect caspase activation.

Venenum bufonis, a Chinese medicine prepared from dried toad skin, has been widely used in the treatment of several types of solid tumors in the People's Republic of China. ${ }^{27}$ The famous ancient TCM book entitled "Compendium of Materia Medica" written by Li in 1590 reported that $V$. bufonis is able to "clean toxics and destroy swelling" and is used to treat boils and pyogenic infection. In the 1990s, an injectable formulation of $V$. bufonis called cinobufacin (huachansu) injection was developed in the People's Republic of China to treat various solid tumors. In 76 patients with gastric cancer, the efficacy of cinobufacin was significantly increased when it was used in combination with docetaxel + cisplatin +5 -fluorouracil. Decreased toxicity and improved life quality were also observed in these patients. ${ }^{28}$ A number of studies have demonstrated that cinobufacin has a significant apoptosis-inducing effect on a variety of cancer cells, ${ }^{29}$ and the caspase-mediated pathway has been found to play an important roles in cinobufacin-induced apoptosis. ${ }^{30}$

Promoting "circulation of the blood to avoid stasis", known as huoxuehuayu in TCM, is one of the strategies used to treat tumors in TCM, and many herbs are recognized to have this activity, including Crocus sativus L. (Iridaceae) and Agrimonia pilosa Ledeb. (Rosaceae). The crocin family is a group of carotenoid esters occurring naturally in C. sativus L. Crocin has been used for the treatment of cancer in the People's Republic of China for many years. Li et $\mathrm{a}^{31}$ showed that crocin $0.5-4 \mathrm{mmol} / \mathrm{L}$ could significantly inhibit the growth of MG63 and OS732 cells, which might be related to upregulation of the expression of caspase- 3 and caspase-8. Extract of $A$. pilosa Ledeb. (50-400 $\mu \mathrm{g} / \mathrm{mL})$, a TCM used to treat various cancers in Asian countries, can induce apoptosis in HepG2 cells by stimulating the apoptotic factors Bcl-2, Bcl-XL, MCL-1, XIAP, BID, BIK, caspase-3, caspase-9, and PARP. ${ }^{32}$

Scutellaria barbata D. Don (Labiatae) is a medicinal herb that has long been used as an antitumor agent in the People's Republic of China and Korea. In TCM, S. barbata D. Don is believed to "clear away heat and toxic material". In recent years, this herb has been combined with other TCMs for the treatment of hepatocellular carcinoma, gastric cancer, colorectal cancer, esophageal cancer, and lung cancer, and the efficacy rates were reported to be $45.5 \%, 90 \%, 92.3 \%, 88.8 \%$, and $66.6 \%$, respectively. ${ }^{33}$ Our recent study has shown that an ethanol extract of S. barbata D. Don (concentration range 12.5-100 $\mu \mathrm{g} / \mathrm{mL}$ ) can inhibit the growth of several types of cancer cells, and a synergistic effect is found when this herb is combined with low-dose 5-fluorouracil, which is closely related to the caspase-mediated apoptosis pathway. ${ }^{34}$ There are reports showing that $S$. barbata D. Don extract $(20-40 \mu \mathrm{g} / \mathrm{mL})$ has anticancer activity via induction of apoptosis, ${ }^{35}$ which might be related to release of cytochrome c from the mitochondria and activation of caspase- 3 in leiomyoma cells. ${ }^{33}$ A chloroform extract of $S$. barbata D. Don (50-200 $\mu \mathrm{g} / \mathrm{mL})$ shows very high cytotoxicity in Bel-7402 cells, and is less cytotoxic to normal liver cells. The chloroform extract of $S$. barbata D. Don can induce apoptosis by releasing cytochrome c and activating caspase- $9 .{ }^{36}$ A methylene chloride extract of $S$. barbata $(5-15 \mu \mathrm{g} / \mathrm{mL})$ also induced apoptosis in human U937 leukemia cells by increasing the ratio of Bax/ Bcl-2, leading to caspase activation. ${ }^{37}$

Some of the compounds in TCM responsible for caspaseinducing activity have been identified. Berberine (Figure 2), a naturally bioactive phytochemical from Coptis chinensis Franch (Ranunculaceae), can induce apoptosis of liver cancer cells via procaspase-9 and its effector caspases, ie, procaspase-3 and procaspase-7. ${ }^{38}$ Wogonin, 5,7-dihydroxy8-methoxyflavone, a flavone constituent of many TCMs, could inhibit the growth of U-2 OS cells in a dose-dependent and time-dependent manner, and treatment with wogonin $75 \mu \mathrm{M}$ has been shown to induce apoptosis via activation of caspase- $3 .{ }^{39}$ 


\section{TCMs that activate reactive oxygen species}

It is well established that generation of intracellular reactive oxygen species (ROS) constitutes a conserved apoptotic event, and production of ROS is a critical determinant of the toxicity of some anticancer agents. ${ }^{40}$ ROS are produced mainly in the mitochondria, so the mitochondria can create adequate oxidative stress, which may ultimately lead to cell death. There is some evidence that ROS can induce apoptosis via several mechanisms, including a mitochondria-dependent or mitochondria-independent pathway. ${ }^{41}$ Some TCMs can prevent oxidative stress-induced apoptosis by helping the body to handle endogenous toxins, ${ }^{42}$ while other TCMs have been reported to destroy tumor cells by generation of ROS. ${ }^{41}$

"Supplementing the center and boosting energy", known as buzhongyiqi in TCM, is another strategy for the treatment of cancer. Herbs with buzhongyiqi activity include Isodon rubescens (Hemsl.) H. Hara (Lamiaceae), Pleurotus abalonus Y. H. Han, K. M. Chen et S. Cheng (Agaricaceae). These types of herbs are usually used in a complementary way to treat cancer in TCM. Recent studies show that treatment of human U-2 OS osteosarcoma cells with crude extract of Cornus officinalis Siebold \& Zucc. leads to apoptotic cell death via ROS-modulated pathways. ${ }^{43}$

Some active compounds able to augment ROS activity have been isolated from TCMs. Shi et al reported that polysaccharides isolated from P. abalonus Y. H. Han, K. M. Chen et S. Cheng. And fractionated into PAP-1, PAP-2, and PAP-3 are very important nutritional ingredients. PAP-3 inhibits the growth of human MCF-7 cancer cells with an $\mathrm{IC}_{50}$ of $193 \mu \mathrm{g} / \mathrm{mL}$. Further study shows that the anticancer effect of P. abalonus Y. H. Han, K. M. Chen et S. Cheng is attributed to the ROS-mediated mitochondrial apoptotic pathway. ${ }^{44}$

The Chinese herb Lithospermum erythrorhizon Sieb. \& Zucc. (Boraginaceae) has been used for centuries in TCM for the treatment of cancer. Duan et al reported that shikonin, a major active component of L. erythrorhizon Sieb. \& Zucc., could induce ROS-mediated apoptosis in human promyelocytic leukemia (HL-60) cells by targeting cytosolic thioredoxin reductase..$^{45}$ Other phytomedicals, such as gambogic acid and curcumin, are also reported to induce tumor apoptosis by targeting the thioredoxin system. ${ }^{21,46}$ Thus, the thioredoxin system might be a new target for treatment of cancer using TCM.

I. rubescens (Hemsl.) H. Hara (Lamiaceae), and Physalisalkekengi L. var. franchetii (Mast.) Makino (Solanaceae) have been used to treat cancer and other swelling related disorders in folk medicine in the People's Republic of China for several decades. A novel diterpenoid known as jaridonin has been isolated from I. rubescens (Hemsl.) H. Hara. Extract of I. rubescens (Hemsl.) H. Hara can inhibit the growth of human esophageal cancer cells (EC109, EC9706, and EC1) in a dose-dependent and time-dependent manner. Its antitumor effects were associated with apoptosis via the ROS-mediated pathway, accompanied by increased expression of $\mathrm{p} 53$, p21waf1/Cip1, and Bax. ${ }^{47}$ Physalin A (Figure 2) is a bioactive anolide isolated from the natural plant Physalisalkekengi $L$. var. franchetii (Mast.), known as jindenglong, and has long been used as a TCM for cancer in the People's Republic of China. Physalin A can inhibit growth of A375-S2 cells in a time-dependent and dose-dependent manner $\left(\mathrm{IC}_{50}\right.$ of 15.04 $\mu \mathrm{M}$ ), and treatment of cancer cells with Physalin A $15 \mu \mathrm{M}$ induced apoptotic cell death and increased generation of ROS. ${ }^{48}$ Longikaurin A (Figure 2) is an ent-kaurane diterpenoid isolated from Rabdosia ternifolia (D. Don) H. Hara (Labiatae). It has been reported that longikaurin A can induce apoptosis via the ROS/JNK/c-Jun pathway in hepatocellular carcinoma cells. ${ }^{49}$

\section{TCMs targeting PI3K/Akt/STAT}

The phosphatidylinositol-3 kinase (PI3K) signaling pathway contributes to the development and progression of many human malignancies. ${ }^{50}$ Activation of the serine/threoninespecific protein kinase Akt, the major downstream effector of PI3K, is frequently observed. ${ }^{51}$ The mechanisms by which Akt promotes cell survival include phosphorylation and inactivation of proapoptotic proteins such as Bad and caspase-9. Akt is also involved in activation of antiapoptotic

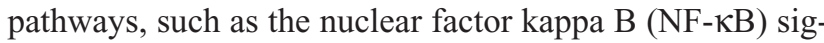
naling pathway.

The TCM formula BDL301 has been used to inhibit inflammation for hundreds of years. Recent studies showed the BDL301 can suppress the STAT3 pathway, resulting in apoptosis in colorectal cancer cells in vitro and in vivo. ${ }^{52}$ In the People's Republic of China, Eriobotrya japonica (Thunb.) Lindl (Rosaceae) and Ziziphus jujuba Miller (Rhamnaceae) are usually used as supplementary herbs for the treatment of patients with certain types of cancer. Recent studies show that ursolic acid (Figure 2), a small molecule compound from E. japonica (Thunb.) Lindl, Z. jujuba Miller, inhibits the growth of gemcitabine-resistant human pancreatic cancer cell lines (MIA PaCa-2, PANC-1, and Capan-1) and induces apoptosis via the JNK and PI3K/ Akt/NF-кB pathways. ${ }^{53}$ 5,7-Dihydroxyflavone, a dietary flavonoid commonly found in many plants, could reduce 
the phosphorylation levels of Akt and STAT3, facilitating the apoptosis of human HepG2 cells, without affecting the viability of normal hepatocytes. ${ }^{20}$

\section{TCMs that downregulate the NF-KB pathway}

Numerous findings have emphasized the importance of the NF- $\kappa \mathrm{B}$ signaling pathway in the development and progression of cancer. ${ }^{54,55}$ Activation of NF- $\kappa B$ leads to either upregulation of antiapoptotic genes (FLIP, cIAP, survivin, $\mathrm{Bcl}-2$, and Bcl-XL) or downregulation of apoptotic genes. A number of antitumor TCMs have been shown to possess inhibitory effects in the NF- $\mathrm{KB}$ signaling pathways. ${ }^{56}$

The root bark of Lycium chinense Miller (Solanaceae), Cortex Lycii Radicis, has been used to treat different inflammation-related symptoms in TCM. Xie et al found that trans- $N$-caffeoyltyramine (Figure 2 ) was the key component responsible for inhibition of NF- $\kappa \mathrm{B}$, with an $\mathrm{IC}_{50}$ of $18.4 \mu \mathrm{M}$. Analysis of the structure-activity relationship suggested that the NF- $\kappa \mathrm{B}$ inhibitory activity of trans- $N$-caffeoyltyramine was related with its Michael acceptor-type structure (an $\alpha, \beta$-unsaturated carbonyl group). ${ }^{57}$ Paeonia lactiflora Pall (Ranunculaceae) is one of the best known herbs in the People's Republic of China, Korea, and Japan. Paeoniflorin (Figure 2), the major bioactive component of peony root, can inhibit NF- $\kappa \mathrm{B}$ transcriptional activity in a dose-dependent manner in lipopolysaccharide-stimulated human colon cancer (HT-29) cells. ${ }^{58}$

Tripterygium wilfordii Hook. f. (Celastraceae), a folk medicine in the People's Republic of China, is used to treat rheumatoid arthritis. A diterpenoid triepoxide component, triptolide (Figure 2), was isolated from T. wilfordii Hook. f. in 1972. Triptolide induces apoptosis by downregulation of $\mathrm{NF}-\kappa \mathrm{B}$ transactivation, and inhibits NF- $\kappa \mathrm{B}$ transcriptional activity by blocking association of the NF- $\kappa B$ subunit $\mathrm{p} 65$ with its cofactor, ie, CREB-binding protein/p300 in the early stage and decreasing the protein level of p65 in the late stage. ${ }^{59}$

Many flavonoid compounds, which are widely distributed in plants, are found to downregulate NF-кB. Scutellaria baicalensis Georgi (Labiatae), one of the most popular herbs in TCM, is described to function as a "heat-clearing and firepurging" agent in the "Compendium of Materia Medica". It is traditionally used to treat swelling and pain in the throat. Three types of flavones, ie, wogonin, baicalein, and baicalin (Figure 2), have been isolated, and their antitumor effects have been evaluated. All three of these flavone components have been found to inhibit growth of several cancer cell lines by scavenging oxidative radicals, leading to inhibition of NF- $\kappa \mathrm{B}$ activity. ${ }^{60}$

\section{TCMs with multiple targets in apoptotic pathways}

Targeting multiple cellular proteins is one of the main properties of TCMs. In addition to downregulation of Bcl-2 and upregulation of Bax, $H$. diffusa Willd extract also affects the p38 mitogen-activated protein kinase (MAPK) pathway; 2-hydroxy-3-methylanthraquinone, isolated from a water extract of $H$. diffusa Willd, showed apoptosis-inducing effects against U937 cancer cells $(20-40 \mu \mathrm{M})$ through activation of p38MAPK and downregulation of p-ERK1/2. ${ }^{61} \mathrm{~S}$. barbata D. Don extract induces cell death via the Bcl-2-mediated apoptotic pathway, ${ }^{37}$ and also suppresses phosphorylation/ activation of Akt and increases p53 expression, resulting in apoptosis of HT-29 cells. ${ }^{62}$

Panax ginseng C. A. Mey (Araliaceae) is a well known herb in TCM, and is described to have the activity of "supplementing the center and boosting energy" (buzhongyiqi activity) in "Compendium of Materia Medica". Several preclinical and clinical studies have demonstrated the anticancer potential of $P$. ginseng C. A. Mey. ${ }^{63}$ A recent US study confirmed that a $1.0 \mathrm{mg} / \mathrm{mL}$ aqueous extract of $P$. ginseng C. A. Mey activates Bax and increases cleaved caspase-3 levels in p21-deficient cells. ${ }^{64}$ In a Korean study, $P$. ginseng C. A. Mey caused apoptosis by downregulating antiapoptotic Bcl-2, Bcl-XL, and IAP family members and activating caspase-3. ${ }^{65}$ Studies have also shown that the antitumor efficacy of ginseng is mainly attributed to saponins, known as ginsenosides. Ginsenosides (Figure 2) are able to induce apoptosis by downregulating expression of c-myc and Bcl-2 and upregulating expression of Fas and p53. ${ }^{66}$ They also induce apoptosis in gastric/colon cancer cells by stimulating the activity of caspase-8, initiating the Fas signaling pathway of apoptosis. ${ }^{67}$ Ginsenosides such as Rh2 $(30 \mu \mathrm{g} / \mathrm{mL})$ induce apoptosis via the death receptor TRAIL-R1/DR4 in the A549 (human lung adenocarcinoma) cell line. ${ }^{68}$ However, a Korean study showed that treatment with red ginseng extract $(0.2-2.0 \mathrm{mg} / \mathrm{mL})$ in the U937 leukemia cell line induces concomitant degradation of poly (ADP-ribose) polymerase, $\beta$-catenin, and PLC- $\gamma 1$ substrate proteins of caspase- 3 , without changing levels of DR4, DR5, and TRAIL. ${ }^{69}$

Brucea javanica (L.) Merr. (Simaroubaceae) is used to treat corns and warts in TCM. B. javanica oil emulsion, from the seed oil of B. javanica (L.) Merr., has been approved by the Chinese regulatory authority to treat lung cancer, 
prostate cancer, and gastrointestinal cancer for many years. Clinical reports showed that combining $B$. javanica oil emulsion with chemotherapy not only increased the anticancer effect but also decreased the toxicity of chemotherapy. ${ }^{70}$ B. javanica oil emulsion induces apoptosis by downregulating expression of $\mathrm{p} 53, \mathrm{Bcl}-2$, and c-myc in hepatocellular and bladder cancer cells ${ }^{71}$ and upregulating expression of Fas in leukemia cells $(125-500 \mu \mathrm{g} / \mathrm{mL}) .^{72}$

Coix lacryma-jobi L. (Gramineae), is recognized to "tonify the spleen and stomach", invigorating the lung heat, expelling wind, and removing dampness. Kanglaite (KLT) injection, extracted from the seed of C. lacryma-jobi L., is an antitumor drug approved by the Chinese regulatory authority, ${ }^{73}$ and the US Food and Drug Administration has also approved a Phase II trial of KLT in the treatment of nonsmall cell lung cancer. The antitumor mechanism of the KLT injection has been investigated in several research centers in the People's Republic of China. It has been demonstrated that KLT induces apoptosis of certain types of cancer cells by upregulating expression of p53, Fas, caspase-3, PCNA, and $21 \mathrm{WAF} 1 / \mathrm{CIP} 1$, and downregulating expression of cyclins $\mathrm{A}, \mathrm{E} 1$, and $\mathrm{F} .{ }^{74}$

Bufalin, the major bioactive component of $V$. bufonis, is a TCM obtained from the skin and parotid venom glands of the toad. ${ }^{30}$ Studies have shown that bufalin induces apoptosis in various types of cancer cells, including hepatocellular carcinoma $(0.001-0.1 \mu \mathrm{M}),{ }^{75}$ colon cancer $(25-100 \mathrm{nM}),{ }^{76}$ leukemia
$(10-12.5 \mathrm{nM}),{ }^{77}$ gastric cancer $(80 \mathrm{nmol} / \mathrm{L}),{ }^{78}$ prostate cancer $(0.1-10 \mu \mathrm{M}),{ }^{79}$ and malignant melanoma $(150-550 \mathrm{nmol} / \mathrm{L}){ }^{80}$ It was reported that bufalin induced apoptosis by affecting Bcl-2/Bax, cytochrome c, caspase-3, PARP, p53, p21 WAF1, cyclin D1, and cyclooxygenase- $2 .{ }^{81}$

\section{Conclusion}

TCM has gained increasing acceptance worldwide in recent years and is being recognized as a rich resource for drug discovery. TCM represents a ray of hope for patients suffering from advanced cancer. ${ }^{82,66}$ TCM is also widely used to reduce the side effects of chemotherapy and improve the outcome of conventional treatment and surgery for cancer. ${ }^{82,83}$ The TCMs discussed here and their effects on apoptotic pathways are summarized in Table 1. Of note, most TCMs containing multiple components exert their antitumor activity by targeting multiple pathways. Although TCMs have been used to treat cancer in the People's Republic of China for thousands of years, their modes of action have not been clearly elucidated. In most cases, TCM extracts have more potent antitumor effects than their individual components, so synergistic effects exist for most TCM preparations. Further in vitro and in vivo studies of the interactions between these components are encouraged. Our recent study reported that the crude extract of clove bud can induce cell death via the apoptotic pathway and inhibit the growth of pancreatic cancer cells both in vitro and in vivo. However, after isolation of

Table I Summary of traditional Chinese medicine and apoptotic pathway targets

\begin{tabular}{|c|c|}
\hline Traditional Chinese medicine & Apoptotic pathway targets \\
\hline $\begin{array}{l}\text { Ethanol extract of Hedyotis diffusa Willd, }{ }^{16} \text { ethanol extracts of Solanum lyratum Thunb } \\
\text { (Solanaceae), }{ }^{19} \text { Rubus aleaefolius Poir total alkaloids, }{ }^{20} \text { gambogic acid, }{ }^{23} \text { telekin }{ }^{24}\end{array}$ & $\mathrm{Bcl}-2 / \mathrm{Bax}$ ratio \\
\hline $\begin{array}{l}\text { Cinobufacin },^{30} \text { crocin }^{31} \text { Agrimonia pilosa Ledeb., }{ }^{32} \text { Scutellaria barbata D. Don, }{ }^{34-37} \\
\text { berberine }{ }^{38} \text { wogonin }^{39}\end{array}$ & Caspases \\
\hline $\begin{array}{l}\text { Crude extract of Cornus officinalis Siebold \& Zucc.., }{ }^{43} \text { polysaccharides of Pleurotus abalonus, } \\
\text { Y.H. Han, K. M. Chen et S. Cheng, }{ }^{44} \text { jaridonin, }{ }^{47} \text { Physalin } A,{ }^{48} \text { Longikaurin } A^{49}\end{array}$ & ROS \\
\hline $\begin{array}{l}\text { Ethanol extract of Scutellaria barbata D. Don, }{ }^{62} \text { ursolic acid, },^{52} 5,7 \text {-dihydroxyflavone, }{ }^{20} \\
\text { traditional Chinese medicinal formula BDL30I }{ }^{52}\end{array}$ & $\mathrm{PI3K} / \mathrm{Akt} / \mathrm{STAT}$ \\
\hline $\begin{array}{l}\text { Triptolide from trans- } N \text {-caffeoyltyramine, }{ }^{57} \text { paeoniflorin, }{ }^{58} \text { Tripterygium wilfordii Hook. f., }{ }^{59} \\
\text { flavones }^{60}\end{array}$ & NF-кB family \\
\hline Panax ginseng C. A. Mey, ${ }^{64-69}$ Brucea javanica Merr., ${ }^{71,72}$ kanglaite injection, ${ }^{74}$ bufalin $^{81}$ & Multiple targets \\
\hline 2-hydroxy-3-methylanthraquinone from $H$. diffusa Willd ${ }^{61}$ & MAPK pathway \\
\hline $\begin{array}{l}\text { Ginsenosides, }{ }^{66} \text { Korean red ginseng extract, }^{67} \mathrm{Rh}^{6,{ }^{68}} \text { seed oil of B. javanica, } \\
\text { kanglaite injection }\end{array}$ & Death receptors \\
\hline Seed oil of B. javanica, ${ }^{71}$ bufalin, $^{81}$ kanglaite injection ${ }^{74}$ & p53 \\
\hline Seed oil of $B$. javanica, ${ }^{71}$ kanglaite injection ${ }^{74}$ & C-myc \\
\hline Shikonin, ${ }^{45}$ gambogic acid, ${ }^{21}$ curcumin ${ }^{46}$ & $\begin{array}{l}\text { Cytosolic thioredoxin } \\
\text { reductase }\end{array}$ \\
\hline Korean red ginseng extract ${ }^{69}$ & $\beta$-catenin \\
\hline
\end{tabular}

Abbreviations: MAPK, mitogen-activated protein kinase; ROS, reactive oxygen species; PI3K, phosphatidylinositol-3 kinase; NF- $\mathrm{B}$, nuclear factor kappa B. 
the bioactive components isolated of this herb, the antitumor effects were weaker when the crude extract was tested in a xenograft nude mouse model, suggesting interactions or synergistic effects between the components. ${ }^{84}$

Although some TCMs have demonstrated efficacy with a reasonable safety profile in clinical trials, most have not been widely studied either clinically or experimentally. Further, TCM is usually used at present as an adjuvant to conventional chemotherapy to reduce side effects. ${ }^{34}$ The need for systematic research and large-scale clinical trials of TCMs in the treatment of cancer should be emphasized.

As already mentioned, apoptosis is one of the main mechanisms by which TCM induces death of cancer cell, but the direct targets involved have not been documented. Further studies are necessary to identify the target molecules of TCMs and their exact antitumor mechanisms. Of note, although apoptosis pathways have been the most extensively studied, other cell death pathways may also be triggered by TCMs; for example, a number of TCMs show anticancer activity by enhancement of immunity. ${ }^{85}$

In recent years, developments in biological technology, such as genomics, transcriptomics, metabolomics, and proteomics, have improved our understanding of the anticancer activity of TCMs. ${ }^{86}$ For instance, the direct binding affinity of ganoderic acid D to 14-3-3 zeta was confirmed by surface plasmon resonance biosensor analysis. ${ }^{87}$ Similar experiments could be performed in the future to isolate the exact mechanisms of the anticancer activity of TCMs. With advances in modern biotechnology, we believe that the mechanisms of TCM will be elucidated and application of these agents in the treatment of cancer will become more widespread.

\section{Acknowledgments}

This work was supported by the Natural Science Foundation of China $(81072065,81273550,81302906)$. The study is also supported in part by the Innovative Drug Development Project of China (2014ZX09102043), Beijing Natural Science Foundation (7144190), and Shandong Provincial Natural Science Foundation (ZR2014HQ031).

\section{Disclosure}

The authors report no conflicts of interest in this work.

\section{References}

1. Li-Weber M. Targeting apoptosis pathways in cancer by Chinese medicine. Cancer Lett. 2013;332(2):304-312.

2. von Schwarzenberg K, Vollmar AM. Targeting apoptosis pathways by natural compounds in cancer: marine compounds as lead structures and chemical tools for cancer therapy. Cancer Lett. 2013;332(2):295-303.
3. Zheng $\mathrm{L}$, Lin $\mathrm{X}, \mathrm{Wu} \mathrm{N}$, et al. Targeting cellular apoptotic pathway with peptides from marine organisms. Biochim Biophys Acta. 2013;1836(1):42-48.

4. Brinkmann K, Kashkar H. Targeting the mitochondrial apoptotic pathway: a preferred approach in hematologic malignancies? Cell Death Dis. 2014;5:e1098.

5. Constantinou C, Papas KA, Constantinou AI. Caspase independent pathways of programmed cell death: the unraveling of new targets of cancer therapy? Curr Cancer Drug Targets. 2009;9(6):717-728.

6. Lin X, Liu M, Hu C, Liao DJ. Targeting cellular proapoptotic molecules for developing anticancer agents from marine sources. Curr Drug Targets. 2010;11(6):708-715.

7. Lin YL, Lai WL, Harn HJ, et al. The methanol extract of Angelica sinensis induces cell apoptosis and suppresses tumor growth in human malignant brain tumors. Evid Based Complement Alternat Med. 2013; 2013:394636.

8. Liu Z, Chen S, Cai J, et al. Traditional Chinese medicine syndromerelated herbal prescriptions in treatment of malignant tumors. J Tradit Chin Med. 2013;33(1):19-26.

9. Chen ZF, Liang H. Progresses in TCM metal-based antitumour agents. Anticancer Agents Med Chem. 2010;10(5):412-423.

10. Jia L, Ma S, Hou X, et al. The synergistic effects of traditional Chinese herbs and radiotherapy for cancer treatment. Oncol Lett. 2013;5(5): 1439-1447.

11. Hsiao WL, Liu L. The role of traditional Chinese herbal medicines in cancer therapy - from TCM theory to mechanistic insights. Planta Med. 2010;76(11):1118-1131.

12. Hardwick JM, Chen YB, Jonas EA. Multipolar functions of BCL-2 proteins link energetics to apoptosis. Trends Cell Biol. 2012;22(6):318-328.

13. Martinou JC, Youle RJ. Mitochondria in apoptosis: Bcl-2 family members and mitochondrial dynamics. Dev Cell. 2011;21(1):92-101.

14. Xiao Y, Ni H. [Analysis of Chen Yi's spirit-regulating and depressionrelieving therapy in treating malignant tumor]. Zhong Hua Zhong Yi Yao Za Zhi. 2010;25(9):1424-1426. Chinese.

15. Liu JB, Yao ZW. [Clinical effects of Hedyotis diffusa injection on primary liver cancer]. Journal of Medical Forum. 2004;25(15):37-39. Chinese.

16. Lin J, Chen Y, Wei L, et al. Hedyotis diffusa Willd extract induces apoptosis via activation of the mitochondrion-dependent pathway in human colon carcinoma cells. Int J Oncol. 2010;37(5):1331-1338.

17. Zhang X, Ye BD, Lin SY. [Effects of Hedyotis diffusa Willd injection on the proliferation of RPMI 8226 cells]. Zhongguo Zhong Xi Yi Jie He Za Zhi. 2012;32(12):1658-1662. Chinese.

18. Yang JS, Wu CC, Kuo CL, et al. Solanum lyratum extracts induce extrinsic and intrinsic pathways of apoptosis in WEHI-3 murine leukemia cells and inhibit allograft tumor. Evid Based Complement Alternat Med. 2012;2012:254960.

19. Lin YT, Huang AC, Kuo CL, et al. Induction of cell cycle arrest and apoptosis in human osteosarcoma U-2 OS cells by Solanum lyratum extracts. Nutr Cancer. 2013;65(3):469-479.

20. Zhang Z, Ye T, Cai X, et al. 5,7-Dihydroxyflavone enhances the apoptosis-inducing potential of Trail in human tumor cells via regulation of apoptosis-related proteins. Evid Based Complement Alternat Med. 2013;2013:434709.

21. Duan D, Zhang B, Yao J, et al. Gambogic acid induces apoptosis in hepatocellular carcinoma SMMC-7721 cells by targeting cytosolic thioredoxin reductase. Free Radic Biol Med. 2014;69:15-25.

22. Zhou Z-T, Wang J-W. [Phase I human tolerability trial of gambogic acid]. Chin J New Drugs. 2007;16(1):79-83. Chinese.

23. Xu J, Zhou M, Ouyang J, et al. Gambogic acid induces mitochondriadependent apoptosis by modulation of Bcl-2 and Bax in mantle cell lymphoma JeKo-1 cells. Chin J Cancer Res. 2013;25:183-191.

24. Zheng B, Wu L, Ma L, et al. Telekin induces apoptosis associated with the mitochondria-mediated pathway in human hepatocellular carcinoma cells. Biol Pharm Bull. 2013;36(7):1118-1125.

25. Fiandalo MV, Kyprianou N. Caspase control: protagonists of cancer cell apoptosis. Exp Oncol. 2012;34(3):165-175. 
26. MacKenzie SH, Clark AC. Death by caspase dimerization. $A d v$ Exp Med Biol. 2012;747:55-73.

27. Qi J, Tan CK, Hashimi SM, Zulfiker AH, Good D, Wei MQ. Toad glandular secretions and skin extractions as anti-inflammatory and anticancer agents. Evid Based Complement Alternat Med. 2014;2014: 312684.

28. Gong ZP, Chen T, Deng LR, Hu YQ. [Research progress on the antitumor clinical application of cinobufagin injection combined with chemotherapy]. Anhui Med Pharm J. 2010;14(1):12-14. Chinese.

29. Qi F, Li A, Zhao L, et al. Cinobufacini, an aqueous extract from Bufo bufo gargarizans Cantor, induces apoptosis through a mitochondriamediated pathway in human hepatocellular carcinoma cells. $J$ Ethnopharmacol. 2010;128(3):654-661.

30. Qi F, Li A, Inagaki Y, et al. Antitumor activity of extracts and compounds from the skin of the toad Bufo bufo gargarizans Cantor. Int Immunopharmacol. 2011;11(3):342-349.

31. Li X, Huang T, Jiang G, Gong W, Qian H, Zou C. Synergistic apoptotic effect of crocin and cisplatin on osteosarcoma cells via caspase induced apoptosis. Toxicol Lett. 2013;221(3):197-204.

32. Nho KJ, Chun JM, Kim HK. Agrimonia pilosa ethanol extract induces apoptotic cell death in HepG2 cells. J Ethnopharmacol. 2011;138(2):358-363.

33. Jin XL. [Research advances on the anticancer pharmacology and clinical application of Scutellaria barbata D. Don]. XianDai YiYao WeiSheng. 2011;27:2154-2155. Chinese.

34. Xu H, Yu J, Sun Y, et al. Scutellaria barbata D. Don extract synergizes the antitumor effects of low dose 5-fluorouracil through induction of apoptosis and metabolism. Phytomedicine. 2013;20(10):897-903.

35. Dai ZJ, Wang XJ, Li ZF, et al. Scutellaria barbate extract induces apoptosis of hepatoma $\mathrm{H} 22$ cells via the mitochondrial pathway involving caspase-3. World J Gastroenterol. 2008;14(48):7321-7328.

36. Yu J, Liu H, Lei J, Tan W, Hu X, Zou G. Antitumor activity of chloroform fraction of Scutellaria barbata and its active constituents. Phytother Res. 2007;21(9):817-822.

37. Cha YY, Lee EO, Lee HJ, et al. Methylene chloride fraction of Scutellaria barbata induces apoptosis in human U937 leukemia cells via the mitochondrial signaling pathway. Clin Chim Acta. 2004;348(1-2):41-48.

38. Yip NK, Ho WS. Berberine induces apoptosis via the mitochondrial pathway in liver cancer cells. Oncol Rep. 2013;30(3):1107-1112.

39. Lin CC, Kuo CL, Lee MH, et al. Wogonin triggers apoptosis in human osteosarcoma U-2 OS cells through the endoplasmic reticulum stress, mitochondrial dysfunction and caspase-3-dependent signaling pathways. Int J Oncol. 2011;39(1):217-224.

40. Panda PK, Mukhopadhyay S, Behera B, et al. Antitumor effect of soybean lectin mediated through reactive oxygen species-dependent pathway. Life Sci. 2014;111(1-2):27-35.

41. Tripathi M, Singh BK, Raisuddin S, Kakkar P. Abrogation of nimesulide induced oxidative stress and mitochondria mediated apoptosis by Fumaria parviflora Lam extract. J Ethnopharmacol. 2011;136(1):94-102.

42. Li F, Wu JH, Wang QH, et al. Gui-ling-gao, a traditional Chinese functional food, prevents oxidative stress-induced apoptosis in $\mathrm{H} 9 \mathrm{c} 2$ cardiomyocytes. Food Funct. 2013;4(5):745-753.

43. Liao CL, Hsu SC, Yu CC, et al. The crude extract of Corni fructus induces apoptotic cell death through reactive oxygen species-modulated pathways in U-2 OS human osteosarcoma cells. Environ Toxicol. 2014;29(9):1020-1031.

44. Shi X, Zhao Y, Jiao Y, Shi T, Yang X. ROS-dependent mitochondria molecular mechanisms underlying antitumor activity of Pleurotus abalonus acidic polysaccharides in human breast cancer MCF-7 cells. PLoS One. 2013;8(5):e64266.

45. Duan D, Zhang B, Yao J, Liu Y, Fang J. Shikonin targets cytosolic thioredoxin reductase to induce ROS-mediated apoptosis in human promyelocytic leukemia HL-60 cells. Free Radic Biol Med. 2014;70:182-193.

46. Cai W, Zhang B, Duan D, Wu J, Fang J. Curcumin targeting the thioredoxin system elevates oxidative stress in HeLa cells. Toxicol Appl Pharmacol. 2012;262(3):341-348.
47. Ma YC, Ke Y, Zi X, et al. Jaridonin, a novel diterpenoid from isodon rubescens, induces reactive oxygen species-mediated apoptosis in esophageal cancer cells. Curr Cancer Drug Targets. 2013;13:611-624.

48. He H, Zang LH, Feng YS, et al. Physalin A induces apoptosis via p53Noxa-mediated ROS generation, and autophagy plays a protective role against apoptosis through p38-NF-kappaB survival pathway in A375-S2 cells. J Ethnopharmacol. 2013;148:544-555.

49. Liao YJ, Bai HY, Li ZH, et al. Longikaurin A, a natural ent-kaurane, induces G2/M phase arrest via downregulation of Skp2 and apoptosis induction through ROS/JNK/c-Jun pathway in hepatocellular carcinoma cells. Cell Death Dis. 2014;5:e1137.

50. Kang XH, Xu ZY, Gong YB, et al. Bufalin reverses HGF-induced resistance to EGFR-TKIs in EGFR mutant lung cancer cells via blockage of Met/PI3k/Akt pathway and induction of apoptosis. Evid Based Complement Alternat Med. 2013;2013:243859.

51. Liu P, Cheng H, Roberts TM, Zhao JJ. Targeting the phosphoinositide 3-kinase pathway in cancer. Nat Rev Drug Discov. 2009;8:627-644.

52. Li J, Liang X, Yang X. Ursolic acid inhibits growth and induces apoptosis in gemcitabine-resistant human pancreatic cancer via the JNK and PI3K/Akt/NF-kappaB pathways. Oncol Rep. 2012;28(2):501-510.

53. Chu L, Zhao H, Fang J, et al. The traditional Chinese medicinal formula BDL301 suppresses tumor growth by inhibiting STAT3 pathway and inducing apoptosis in colorectal cancer cells. DNA Cell Biol. 2015;34(3):178-188.

54. Schneider G, Kramer OH. NFkappaB/p53 crosstalk: a promising new therapeutic target. Biochim Biophys Acta. 2011;1815(1):90-103.

55. Ni H, Zhao W, Kong X, Li H, Ouyang J. NF-kappa B modulation is involved in celastrol induced human multiple myeloma cell apoptosis. PLoS One. 2014;9:e95846.

56. Li F, Sethi G. Targeting transcription factor NF-kappaB to overcome chemoresistance and radioresistance in cancer therapy. Biochim Biophys Acta. 2010;1805:167-180.

57. Xie LW, Atanasov AG, Guo DA, et al. Activity-guided isolation of $\mathrm{NF}-\mathrm{\kappa B}$ inhibitors and PPAR $\gamma$ agonists from the root bark of Lycium chinense Miller. J Ethnopharmacol. 2014;152(3):470-477.

58. Zhang J, Dou W, Zhang E, et al. Paeoniflorin abrogates DSS-induced colitis via a TLR4-dependent pathway. Am J Physiol Gastrointest Liver Physiol. 2014;306(1):G27-G36.

59. Zhu W, Ou Y, Li Y, et al. A small-molecule triptolide suppresses angiogenesis and invasion of human anaplastic thyroid carcinoma cells via down-regulation of the nuclear factor-kappa B pathway. Mol Pharmacol. 2009;75:812-819.

60. Li-Weber M. New therapeutic aspects of flavones: the anticancer properties of Scutellaria and its main active constituents wogonin, baicalein and baicalin. Cancer Treat Rev. 2009;35:57-68.

61. Wang N, Li DY, Niu HY, Zhang Y, He P, Wang JH. 2-hydroxy-3methylanthraquinone from Hedyotis diffusa Willd induces apoptosis in human leukemic U937 cells through modulation of MAPK pathways. Arch Pharm Res. 2013;36:752-758

62. Wei L, Lin J, Wu G, et al. Scutellaria barbata D. Don induces G1/S arrest via modulation of p53 and Akt pathways in human colon carcinoma cells. Oncol Rep. 2013;29:1623-1628.

63. Nag SA, Qin JJ, Wang W, et al. Ginsenosides as anticancer agents: In vitro and in vivo activities, structure-activity relationships, and molecular mechanisms of action. Front Pharmacol. 2012;3:25.

64. King ML, Murphy LL. Role of cyclin inhibitor protein p 21 in the inhibition of HCT116 human colon cancer cell proliferation by American ginseng (Panax quinquefolius) and its constituents. Phytomedicine. 2010;17:261-268.

65. Cheng CC, Yang SM, Huang CY, Chen JC, Chang WM, Hsu SL. Molecular mechanisms of ginsenoside Rh2-mediated G1 growth arrest and apoptosis in human lung adenocarcinoma A549 cells. Cancer Chemother Pharmacol. 2005;55:531-540.

66. CX Pan, Morrison RS, Ness J, Fugh-Berman A, Leipzig RM. Complementary and alternative medicine in the management of pain, dyspnea, and nausea and vomiting near the end of life. A systematic review. J Pain Symptom Manage. 2000;20:374-387. 
67. Yi JS, Choo HJ, Cho BR, et al. Ginsenoside Rh2 induces ligandindependent Fas activation via lipid raft disruption. Biochem Biophys Res Commun. 2009;385(2):154-159.

68. Choi K, Choi C. Proapoptotic ginsenosides compound K and Rh2 enhance FAS-induced cell death of human astrocytoma cells through distinct apoptotic signaling pathways. Cancer Res Treat. 2009;41:36-44.

69. Park SE, Park C, Kim SH, et al. Korean red ginseng extract induces apoptosis and decreases telomerase activity in human leukemia cells. J Ethnopharmacol. 2009;121:304-312.

70. Wang HM, Liao GQ, Liu PH, Qu YM, Xie GQ, Liu SX. [Clinical study on the treatment of malignant pleural elusions by intracavitary application with cisplatin combined with Brucea javanica oil emulsion]. Zhong Guo Xian Dain Zhong Yao. 2009;9:23-24. Chinese.

71. Ma L, Zhang YN. [Effects of seminal oil emulsion of Brucea javanica on apoptosis and apoptosis-related genes in human hepatocellular carcinoma cells]. World Chinese Journal of Digestology. 2004;12:559-562. Chinese.

72. Li Y, Li Y, Zhang LY, Xu GL. [Experimental study of Brucea Javanica oil emulsion induceds K562 cell apoptosis and its mechanism]. J Int Oncol. 2006;33:637-639. Chinese.

73. Li CG, Huang XE, Xu L, Li Y, Lu YY. Clinical application of serum tumor associated material (TAM) from non-small cell lung cancer patients. Asian Pac J Cancer Prev. 2012;13:301-304.

74. Zhu L, Yang Z, Wang S, Tang Y. [Kanglaite for treating advanced non-small-cell lung cancer: a systematic review]. Zhongguo Fei Ai Za Zhi. 2009;12:208-215. Chinese.

75. Qi F, Inagaki Y, Gao B, et al. Bufalin and cinobufagin induce apoptosis of human hepatocellular carcinoma cells via Fas- and mitochondriamediated pathways. Cancer Sci. 2011;102:951-958.

76. Xie CM, Chan WY, Yu S, Zhao J, Cheng CH. Bufalin induces autophagy-mediated cell death in human colon cancer cells through reactive oxygen species generation and JNK activation. Free Radic Biol Med. 2011;51:1365-1375.

77. Amano Y, Cho Y, Matsunawa M, Komiyama K, Makishima M. Increased nuclear expression and transactivation of vitamin D receptor by the cardiotonic steroid bufalin in human myeloid leukemia cells. J Steroid Biochem Mol Biol. 2009;114:144-151.
78. Li D, Qu X, Hou K, et al. PI3K/Akt is involved in bufalin-induced apoptosis in gastric cancer cells. Anticancer Drugs. 2009;20:59-64.

79. Yu CH, Kan SF, Pu HF, Jea Chien E, Wang PS. Apoptotic signaling in bufalin- and cinobufagin-treated androgen-dependent and -independent human prostate cancer cells. Cancer Sci. 2008;99:2467-2476.

80. Hsiao YP, Yu CS, Yu CC, et al. Triggering apoptotic death of human malignant melanoma a375.s 2 cells by bufalin: involvement of caspase cascade-dependent and independent mitochondrial signaling pathways. Evid Based Complement Alternat Med. 2012;2012:591241.

81. Jiang Y, Zhang Y, Luan J, et al. Effects of bufalin on the proliferation of human lung cancer cells and its molecular mechanisms of action. Cytotechnology. 2010;62:573-583.

82. McCulloch M, See C, Shu XJ, et al. Astragalus-based Chinese herbs and platinum-based chemotherapy for advanced non-small-cell lung cancer: meta-analysis of randomized trials. J Clin Oncol. 2006;24:419-430.

83. Li L, Leung PS. Use of herbal medicines and natural products: an alternative approach to overcoming the apoptotic resistance of pancreatic cancer. Int J Biochem Cell Biol. 2014;53:224-236.

84. Liu H, Schmitz JC, Wei J, et al. Clove extract inhibits tumor growth and promotes cell cycle arrest and apoptosis. Oncol Res. 2014;21:247-259.

85. Ren Z, He C, Fan Y, et al. Immuno-enhancement effects of ethanol extract from Cyrtomium macrophyllum (Makino) Tagawa on cyclophosphamide-induced immunosuppression in BALB/c mice. J Ethnopharmacol. 2014;155:769-775.

86. Lu JJ, Dang YY, Huang M, Xu WS, Chen XP, Wang YT. Anti-cancer properties of terpenoids isolated from Rhizoma curcumae - a review. J Ethnopharmacol. 2012;143:406-411.

87. Yue QX, Cao ZW, Guan SH, et al. Proteomics characterization of the cytotoxicity mechanism of ganoderic acid D and computer-automated estimation of the possible drug target network. Mol Cell Proteomics. 2008;7:949-961.
Drug Design, Development and Therapy

\section{Publish your work in this journal}

Drug Design, Development and Therapy is an international, peerreviewed open-access journal that spans the spectrum of drug design and development through to clinical applications. Clinical outcomes, patient safety, and programs for the development and effective, safe, and sustained use of medicines are a feature of the journal, which

\section{Dovepress}

has also been accepted for indexing on PubMed Central. The manuscript management system is completely online and includes a very quick and fair peer-review system, which is all easy to use. Visit http://www.dovepress.com/testimonials.php to read real quotes from published authors. 